\title{
Research on Bottleneck Analysis and Solution of Restricting Employment of the Vulnerable Groups of College Students
}

\author{
Yang Zhang \\ Wuxi institute of Commerce Department of students' work, Wuxi, Jiangsu 214153 \\ Jiangsu province Wuxi City QianHu Road No. 809 Wuxi Institue of Commerce 214153 \\ 84683418@qq.com
}

Keywords: College students; Vulnerable group; Employment bottleneck; Route

\begin{abstract}
Under the background of "labor shortage" and "difficult employment", deep analyze of the current situation and causes of restricting the employment bottleneck of vulnerable group of College students, Understand the law of employment behavior and influencing factors of the vulnerable groups of College students, analyze and study the existing problems and the reasons of formation, to find a systematic solution to the problem. Government improves public policy and system supply, to provide a better employment environment. Colleges and universities strengthen and improve the vocational guidance for college students, enhance the employability of the disadvantaged groups of students, to help students to assess the employment, the correct understanding of the employment situation, improve their comprehensive ability.
\end{abstract}

\section{Introduction}

With the adjustment of economic and industrial structure, the problem of employment of college students is becoming more and more difficult, which has become one of the most important social problems. With the expansion of college enrollment leaded to the number of college graduates with high innovation. In employment growth rate lagged the pace of growth in the number of graduates, graduate employment rate is in a downtrend, obvious difference in the degree of different professional orientation of employment. The phenomenon of College Students' employment after employment is generally caused by the University's talent training mode is difficult to adapt to the actual demand of human resources market, resulting in the contradiction between supply and demand of College Students' employment market.

The vulnerable group of college students is the social vulnerable groups in Colleges and universities, is a social transition period of institutional changes in the development of derivatives. In 2016, 7 million 650 thousand college graduates in China reached the highest in history, and the employment of disadvantaged groups in college students is facing greater pressure. The reasons for the formation of the disadvantaged groups of college students mainly include family, economy, society, education, self and other factors, which have the characteristics of higher educational level, strong ability of transformation and large negative influence. In recent years, with the increasing pressure of social employment competition, the "threshold" of employment being higher and higher, the weak group of college students in Colleges and universities has been expanding. In the process of employment due to the understanding of deviation and psychological problems caused by the discrimination and injustice etc., the difficult problem of employment not only restricts the development of the individual, but also affects the social harmony and stability. Student's difficult employment problems are more prominent, which has become a hot and difficult issue of social concern.

\section{Current Employment Bottleneck Situation of College Students}

China's new labor force every year in about 20 million, due to the limited capacity of the education, the annual need of employment in new labor population is between 1000 to 1600 million, and according to the relevant expert's estimation assumed economic growth rate of $8 \%$, employment 
elasticity coefficient of 0.13 , it per year can provide jobs for about 800 million, and the gap is obvious. In 2016 there are 765 million college graduates nationwide, and after secondary school, technical school and junior high school graduates who don't continue their studies no longer, as well as the need to transfer employment of rural surplus labor force. Under the background of the slowdown in economic growth, downward pressure on the economy continuing to increase, the industrial structure adjustment, the supply is over the labor market, due to the lack of work experience, competitiveness is not strong leading to the problem of employment of college students become increasingly prominent.

The employment difficulty of college students is mainly reflected in College Students with current family economic difficulties, College Students lacking of social relations, college students with low employment quality, physical and psychological defects, graduates Employment with blocked, low degree of employment competitiveness. Under the environment of economic development and social transformation, due to cultural differences, regional differences, urban and rural dual economic differences of social problems, people have a cognitive bias which leads that the disadvantaged group of college students in the employment process, cannot be accepted and recognized by society, by the discrimination, unable to realize the equal employment, increase the difficulty of the employment of the disadvantaged group of College Students.

College students is restricted by economic, cultural and environmental factors in the course of education, Leaded that knowledge is relatively narrow, social experience is lacking, these differences in the cultural capital is difficult to pass in a short period of time to improve the study, resulting in a college student disadvantaged in employment in the process of de facto inequality. From the current situation, the disadvantaged group of college students first in the course of employment generally facing three problems. From the current situation, the disadvantaged group of college students first in the course of employment generally faces three problems: First, the choice of an ideal career is difficult; second, stable job is difficult; third, being professional counterparts and using what you learn are difficult.

The difficulties of College Students' employment exposed the institutional dilemma of College Students' employment and structural conflict, but its essence is the result of offside and absence of government functions of market failure. The number and proportion of different professional talents in Colleges and universities and the imbalance of social demand or the mismatch between different professional graduates in short supply and the phenomenon of oversupply of employment contradictions, are the main "bottleneck" restricting the employment of college students, and affect the quality of employment.

The weak group of college students in the process of achieving employment, by the impact of internal and external factors, so it can effectively broaden the channels of employment and find the characteristics of the work in line with their own characteristics in the process of obstacles encountered in the process. The social equality and competition of the employing mechanism is still not perfect today, the personal social background and family owned social network capital on the employment of college students is still great. College graduates cannot really reach the standard for enterprise of "success", knowledge, ability and quality.

\section{Analysis of Employment Bottleneck of College Students in the Disadvantaged Groups}

Labor Supply and Demand Are Serious Imbalanced. The serious imbalance between supply and demand of labor force is the basic reason for the difficulty of the employment of college students. Our country is a country with abundant labor resources and relatively scarce capital, the per capita share of capital is very low, under certain conditions, the ability of capital to absorb the labor force is limited. Non-human capital surplus labor is the basic characteristics of the employment market in China, from the strict economic sense, the full employment in our country can only be a long-term employment target, the cannot be achieved at current stage. In the process of Chinese economic transformation from extensive to high and new technology, high added value, the demand for low labor force is sure to reduce. In addition, the proportion of the third industry is small, is still not developed, which restricts the number of jobs. And 2015 to 2020 is still the period of the continued 
growth of China's working age population, coupled with the transfer of rural youth industry, the employment market caused by another round of the impact. Under this kind of background, the employment of the strong group has a certain gap, not to mention the employ the disadvantaged groups. Therefore, the employment situation of vulnerable groups to employ will continue for a long time. The market competition mechanism in the system of employment of vulnerable groups becomes a victim of ruthless employment market. Under the condition of market economy, enterprises are often more willing to employ the workers with high quality and skill level, rich work experience and high Technical price ratio, the disadvantaged group of college students in terms of quality, skill level and work experience as well as lack excluded by the labor market.

Migrant Workers into the City Bringing Employment Substitution Effect. With the accelerated process of urbanization, more and more farmers go to work in the city. In 2015, the total amount of migrant workers is 277 million 470 thousand, of which 168 million 840 thousand migrant workers work outsides. The industries they entered become more and more wide, due to the migrant workers this certain group of certain jobs in a particular position, which led to the other groups cannot effectively occupy the position. Migrant workers in the city at the informal sector havw a strong employment competitiveness, and with the disadvantaged groups of college students in the employment market to start direct competition. This kind of competition deduction brings vulnerable group of university students the elimination rate to rise in the employment market. As farmers enter the potential employees to adapt to the needs of specific jobs, the disadvantaged groups of college students have a certain degree of employment alternatives. Under the dual pressures of "machine exclusion" and "migrant workers substitution", the employment space of college students is becoming increasingly narrow, which further increases the employment difficulties of college students.

The Government and the Society Give the Vulnerable Group of University Students Insufficiency of Employment Relief. Countries although formulated a series of policies to promote the employment of the college students, but in the process of implementing, unit of choose and employ persons fancy graduates education, graduation school background factors, over the pursuit of high degree, artificially increased the employment threshold, resulting in the disadvantaged group of college students in the face of some high quality jobs with no fair participation opportunities. When employment difficulties are not a small number of cases but a group phenomenon, it will affect the enthusiasm of people to invest in Higher Education in a large scale. Also a large number of unemployed universities graduates or not full employed, not only affects the sustainable economic development and social harmony and stability, but also leads to the waste of talent resources and higher education resources.

Reasons for Colleges and Universities. The social and economic conditions are directly reflected in the economic status of the profession and the economic situation of the industry. Structural contradictions in the employment of graduates, performs as professional and demand, the level of imbalance between demand and the phenomenon. Because the frequency of the school training period and the change of the social demand are not synchronous, the adjustment of the school lags behind the social demand. There is a great supply and demand dislocation between new demand of market economy and the adjustment of industrial structure to college students and the employment of the current university students. It is difficult to examine the quality of talent training from the perspective of social demand, which is the only standard for the evaluation of students' training, which results in the deviation of the training direction. Because the weak group of college students do not have the skilled skills, they are easy to be impacted by economic factors, like the continuous transformation of the job and lack of loyalty to the enterprise. Leading enterprises prefer to recruit workers with rich work experience of skilled, even in the "labor shortage" the plight of enterprises, is also not willing to spend time and energy to develop the initial employment of university graduates, further reducing the of the disadvantaged group of college students employment options. At the same time, colleges and universities attach great importance to employment, only pursuing high employment rate, but the employment information resources and service system is not perfect. The shortage of professional guidance teachers, who are specialized, 
also restricts the employment ability of college students.

Reasons for the Weak Group of College Students. The disadvantaged groups of college students mainly come from the lower level of rural and urban areas, which in terms of the amount and quality of social resources are relatively poor, the support from the family economic and social relations are less, and analysis on the occupation in the employment of information access is relatively insufficient. Because of the influence of the environment, the knowledge, ideas, ways of thinking of the disadvantaged groups of college students, as well as the cause of the expectations with the strong group of college students have a certain difference. Forming differences at pre University education, the disadvantaged group of college students chooses the occupation in conjunction with their professional at the same time, focusing on economic choice, hoping that they will be sent to the developed regional and urban areas, and have a good development prospects, are not willing to work in the grass-roots level and less developed areas, resulting in the employment of the choice of narrow face. On the professional orientation for instant success, lacking of long-term planning, in the employment mentality, they performs for status, for the stable and fear of risk taking. Once the career setback or lost the competition, they are easy to show complaining, inferiority and abandonment and some bad psychological inferiority. With the translation of social economy and the increasing pressure of employment competition, the "threshold" of employment being constantly improving, the weak group of college students in exchange, cooperation, solving problems, lacks of comprehensive quality, resulting in a great deviation between the ideal and the social reality. College students shoe the utility tendency of in the employment process, resulting Structural contradictions in the allocation of human resources supply and demand. The disadvantaged group of college students is difficult to compete with other dominant families in choosing a career, unable to have their own ideal position, resulting in the employment difficulties.

\section{Research on the Path of Solving the Employment Bottleneck of Weak Group of College Students}

The number of vulnerable groups of college students is more and complex, needing a full range of social support for the vulnerable groups of College students. According to the specific circumstances of the students , carry out guidance and help, from the economic support to social assistance, from the promotion achievement to personalized service, to meet diverse student needs support, through a full range of education service system to improve college students their own ability and quality.

Government Improve Public Policy and System Supply, to Provide a Better Employment Environment. Through the formulation and implementation of social policy, the government provides a better public policy and institutional arrangement for the "full employment of college students", and a better employment environment and providing better service. Through public policy and institutional arrangements, give more policy support to the vulnerable groups of College students. Government departments should give full play to the norms of the system, the mandatory role, to create an open and fair competition environment and social environment, to eliminate various institutional obstacles which is not conducive to the disadvantaged group of college students employment, to break the barriers between urban and rural areas and among regions, to realize the equality of employment opportunities, take practical and effective measures to encourage college students to places of employment, so as to adjust the different parts of the structural contradictions of the employment. At the same time, in view of the dense current large city center city population, lead to employment difficulties, reasonable guide urban population distribution and employment structure, and promote the urban function layout and population structure distribution.

Strengthen and Improve Vocational Guidance for College Students. The vulnerable group of college students is a special group in the process of growing up from the youth to adulthood. The internal causes of the multiple values and the re constitution of the personality and the common effects of the environmental factors, the psychological health of college students is worse than that of other stages. At present, most college students lack of psychological preparation for the employment situation, lack of targeted employment guidance. More the number of the vulnerable 
group of college students and complex causes, need schools according to the specific circumstances of the students to carry out guidance and help, from the economic support to social assistance, from the promotion achievement to personalized service, to meet the diverse student needs support, through a full range of education service system to improve college students their own ability and quality. Colleges and universities should change the mode of talent cultivation, whose professional set to show the market orientation, to adapt to the needs of the job market, adding social needs of professional courses and elective courses, optimizing the knowledge structure of College students. Offer the employment guidance course, feedback the employment information in time, grasp the ideological trend of the employment of College students, to carry out the employment consulting service, so that the college students can know themselves objectively, and establish the reasonable employment expectation.

Enhance the Employment Ability of Disadvantaged Groups of College Students. The employment ability of college students is difficult to meet the practical needs of employers, which is an important reason for the difficulty of College Students' employment. At the same time, the low employment ability will lead to college students' employment with low wages and benefits, slim career prospects, directly affecting the quality of College Students' Employment. To enhance the employability of college students, on the one hand, higher education training mechanisms are able to respond quickly to changes in the market demand for talents, with organization, planning to teach students in accordance with their aptitude, so that the school education can keep pace with the actual demand of society on people's knowledge and skills, so as to make the students to quickly enter the state of occupation; On the other hand, strengthen the cultivation of College Students' professional quality and professional spirit, in order to adapt to the increasingly fierce competition environment. At the same time, in the face of the rapid development of knowledge economy, but also strengthen research on lifelong learning system and construction, through continuous learning to improve vocational employment ability of the disadvantaged group of college students to adapt to the needs and satisfy the position of knowledge and skills.

Set up the Correct Employment View, Rationally Choose Post. With the changing of social background, the employment of university students will go from "elite" to "popular", in the process, part of the student's employment standards and social evaluation of talent has not been achieved really a "popular" transformation. Along with the change of the employment situation, college students should update their concept of employment and the disadvantaged group of college students should correctly understand and analyze the employment environment, to find the favorable factors and avoid the unfavorable factors, work out in line with the social actual career goals. At the same time, have a correct understanding on their own, adjust good mentality in career selection and reasonably determine the employment expectations, put themselves in a correct position, strive for take the initiative in the competition for jobs. College students during the period of school, pay attention to the cultivation of professional ability, take career planning as the breakthrough point, with a correct understanding of its own characteristics and the potential advantages, on their value of comprehensive orientation, understand the employment situation and policies, understand the social and professional, raise awareness of employment competition, form a correct view of employment and employment concept, achieve personal career development.

\section{References}

[1] Ye Xinyu. Talent bottleneck of small and medium sized enterprises and analysis of employment difficulties of College Students Deconstruction based on the perspective of employment[J].Enterprise economy, 2014 (2): 78-82.

[2] Ma Tingqi. Stakeholders and college students' employment system reform [J].Research on higher engineering education, 2015 (1): 51-55.

[3] Tan Qinggang. Institutional unemployment and difficult employment of college students in China [J]. population and economy, 2011 (1): 22-26 
[4] Cao Hongjun, Wang Yizun. Structural contradictions of the employment of college students on professional [J].Academic forum, 2014 (7): 168-172

[5] Wang Ting, Zhang Ting. Study on the employment quality of College Students under the background of expanding employment strategy [J]. Research on Higher Education in China, 2014 (2): $26-30$ 